Article

\title{
How to Wiki in Moodle or Sakai
}

\section{Collaboration for Online Language Learning}

\author{
Bridget Yaden \\ Pacific Lutheran University \\ Patrick Blaine \\ University of Washington
}

\section{Introduction}

The rising costs and increasing lack of flexibility of commercial web course management tools such as WebCT and Blackboard have prompted many universities and language departments to consider open source software alternatives. At the University of Washington in Seattle, and Pacific Lutheran University in Tacoma, Washington, two of the most popular open source learning management systems (LMS) have been implemented. They are Moodle and Sakai. This paper describes three pilot projects that had as their main goals the assessment of current language faculty use of an LMS in their courses, the integration of Wikis into language, literature, and linguistics courses, and finally the exploration of new and effective uses of the Wiki tool.

\section{Theoretical Considerations}

Increasingly, the term LMS (learning management system) is replacing the term CMS (course management system) as a result of a significant shift in the pedagogical beliefs underlying the potential uses for these technological resources. CMS indicates a more teacher-centered class where the teacher manages the content whereas LMS connotes a more student-centered class where the learner manages the content. The more "traditional" CMS programs are based on a teacher-centered approach where students are merely the recipients of knowledge transmitted by the teacher. The theory of constructivist learning informs the student-centered approach to learning/teaching available via an LMS, where teachers facilitate as students construct knowledge. In the student-centered constructivist model, knowledge is socially constructed, rather than received (Richards and Rodgers 2001). The students produce the content, learn by actively doing, and create meaning by working together. Looking at L1 acquisition as a model for L2 learning, the socio-constructivist theory argues that through interactions with others, linguistically speaking, a child is able to advance to a higher level of knowledge and performance than he or she would be capable of independently (Lightbown and Spada 1999). 
Communicative, task-based, interactionist, and content-based approaches benefit from the kinds of collaborative activities in which students can participate via the tools in LMS such as Moodle and Sakai, especially when done in the L2. Students naturally negotiate meaning as they work together to articulate their messages, clarify definitions, and solve problems together. The synchronous and asynchronous tools available in an LMS, in particular the Wiki tool as described below, offer a means to encourage a more student-centered learning experience in language classrooms.

\section{Open Source Learning Management Systems: Moodle and Sakai}

\section{Overview}

Moodle and Sakai are two different LMS products based on open source programming that have been recognized by many in the educational community as creating a reliable, adaptable, modular system with sound pedagogical tools for learning. The various modules available in these systems have immediate and seamless applications that can be used in a language course, whether it be an online, hybrid, or traditional class. These module types will be outlined below, with a special focus on three pilot class projects involving Wikis, a tool designed specifically for collaborative projects.

These LMS products are free, pedagogically sound, and continue to be improved daily by a community of programmers and developers from around the world. They can also provide a good alternative to proprietary LMS or CMS systems, which can cost upwards of $\$ 40,000$ per year in licensing fees. Moodle and Sakai contain a number of different features that enable communication between individuals and groups through features such as email, discussion boards, and chat rooms. Also, these learning management systems allow for the easy online creation and integration of pedagogical exercises commonly used in language teaching, such as multiple-choice, fill-in, and short answer questions. Teachers and developers can easily post resources such as documents and links to external websites in their on-line learning space. Technically advanced developers can also add RSS feeds with audio and video streaming (podcasts).

It should be mentioned that despite the fact that there is no "up-front" cost for using this software, the actual implementation and maintenance of it does require a significant investment in patience and man hours, as well as some equipment. Technical support issues can sometimes be fairly difficult to solve and bring the system to halt, which is disruptive during an academic term. Solutions can usually found after reading and posting to forums, and a great deal of trial and error. For anything more than a test installation, either platform also requires at least one dedicated server to run properly, and depending on the number of users involved, can get fairly complex.

One way to circumvent these possible problems, and have professional installation, maintenance, and technical support is to use commercial hosting. A number of commercial partners will host a Moodle or Sakai installation, and can take a large amount of headache out of the whole process, leaving an institution free to focus on using the software, rather than on purely making it function. More companies provide this service for Moodle, and they even have a dedicated website ${ }^{1}$. The cost of commercial hosting is significantly lower than the cost of commercial LMS products, so this can be a very attractive option for institutions whose IT staff is already overloaded, or does not possess sufficient expertise in the technologies required to run and maintain an LMS on their own. It also greatly increases the speed and reliability with which a program could be implemented. An important part of the learning curve with either program is a proper installation. 


\section{Moodle}

Moodle $^{2}$ stands for Modular Object Oriented Development Learning Environment. It allows developers the choice between a number of modules with different functions to find what works best for them. This makes the software effective and useful for online courses, discussion portals, collaborative meeting and socializing. Moodle is used by more than 70,000 institutions and individuals, whose sites serve an exponentially higher number of users. It is currently used to teach 70 languages in 130 countries, and it is fully Unicode compliant. One example of a large online course initiative based on the Moodle system is housed at the Language Learning Center ${ }^{3}$ at the University of Washington. This initiative includes courses in Arabic, Biblical Hebrew, Czech, German, Indonesian, Japanese, Linguistics, Russian, Spanish, and Swedish. For many institutions, one of the most appealing aspects of Moodle is its flexibility in terms of installation. For full functionality, the software must be installed on a webserver, which users access from the internet. It is also possible, however, to place Moodle on standalone computers, and upload courses, glossaries, and other course materials to the installation. Moodle can be installed on Linux, Windows, and Mac operating systems, and can be installed manually or through installation packages.

Moodle is PHP-based, and is dependent on a database, usually MySQL. This means that whether it is installed on a server, personal desktop, or laptop, part of the process will include installing PHP and MySQL as well. If one has the expertise or capability, it is preferable to run Moodle on a Linux machine, although it is not necessary. Linux tends to be more stable and less resource-hungry than Windows as a server platform. What's more, Moodle and all the open-source software it depends on is mainly designed with Linux as its intended operating system, although it will function on Windows and even Mac OSX. Finally, in order to integrate it into existing networks, Moodle is compatible with a large number of authentication protocols.

Moodle has 11 modules, including Lesson, Quiz, Wiki, Forum, Chat, Assignment, Glossary, Forum, and Workshop. Webpages can be linked or composed internally and the entire site is editable in a WYSIWYG interface, which makes it easy to learn and modify. Nearly all the features can also be edited using HTML code as well, and there are numerous plug-ins that can augment its native functionality. The Glossary function in Moodle can also function collaboratively, allowing for the compilation of a searchable glossary made by all site users. In addition, it has incorporated blogging capabilities recently.

\section{Sakai}

The Sakai Project ${ }^{4}$ was founded by the University of Michigan, Indiana University, MIT, Stanford, the uPortal Consortium, and the Open Knowledge Initiative (OKI) with the initial help of a Mellon grant. In 2005 the Sakai Foundation was organized as a non-profit corporation, with the goal of providing a common place to coordinate efforts. Research collaboration was also an initial goal of Sakai. Anyone can use, modify, and distribute all or parts of Sakai without any obligation to join as a Sakai Partner. According to the Sakai Project website, institutions that are interested in becoming "Sakai Partners" in order to participate in the governance of the foundation and its operations can do so by paying $\$ 10,000$ per year ( $\$ 5,000$ for smaller colleges).

The name Sakai is not an acronym like Moodle. It comes from the "Iron Chef" Hiroyuki Sakai, a Japanese French fusion cooking chef. Sakai is Java-based and currently requires Java 1.4.2. According to the Sakai Project website, developers are considering the possibility of making the software available in 
other languages such as JSP, PHP, and Perl. Both MySQL and Oracle are currently supported by Sakai 2.1, but setting them up to support Sakai requires some additional configuration. Sakai has modules similar to those of Moodle, with similar titles: Chat Room, Discussion, Workspace, Quiz and Test Tool, Resources Tool, and Email Archive. Sakai is modular, like Moodle, so that an institution can install different modules as stand-alones or as additions.

\section{Collaboration within Moodle and Sakai}

For collaborative, social, or group applications, a number of options exist in both Moodle and Sakai. These can be either synchronous (meaning users are collaborating live, in real time) or asynchronous (meaning that the collaboration does not require users to be working at the same time). Table 1 outlines the collaborative tools in each system.

Table 1: Collaborative Tools in Moodle and Sakai

\begin{tabular}{ll}
\hline Synchronous & Asynchronous \\
\hline Chat (Moodle) & Forum (Moodle) \\
$\begin{array}{l}\text { Chat Room (Sakai): Groups of people can gather } \\
\text { online for a text-based chat that can either be } \\
\text { moderated or unmoderated. }\end{array}$ & $\begin{array}{l}\text { Discussion Tool (Sakai): This allows for posting } \\
\text { discussions among a number of people. }\end{array}$ \\
$\begin{array}{ll}\text { Messenger (Moodle) } \\
\text { Email Archive Tool (Sakai): This function is }\end{array}$ \\
$\begin{array}{l}\text { Wimilar to Microsoft or AOL instant messenger. If } \\
\text { designed for the creation of collaborative } \\
\text { the other person is not online, they will be sents done in a nested hierarchy, which any } \\
\text { an email. }\end{array}$ & $\begin{array}{l}\text { member of the group may add to, modify, or edit. } \\
\text { informational website together. }\end{array}$ \\
& $\begin{array}{l}\text { members essentially create an } \\
\end{array}$
\end{tabular}

\section{Collaborative workspaces: Wikis}

\section{Introduction to Wikis}

Wikis are online spaces for collaborative projects outside of the classroom. Wiki wiki is actually Hawaiian for quick. Many people are familiar with wikipedia.com, which is itself a Wiki in the form of an online encyclopedia that can be edited by any user. "WikiWikiWeb" was created in 1995 by Ward Cunningham as an online manual for software programmers to share knowledge (Taylor 2005). Jimmy Wales built on this idea and created wikipedia.com, and now Wikis are used in business settings for projects and collaborations within and across companies. Educators are now experimenting with using Wikis in pedagogically sound ways. 
Wikis are part of a set of technology tools that Godwin-Jones calls second generation web that foster increased collaboration between users (Godwin-Jones 2003). Each user has the ability to modify any part of the Wiki space, analogous to a mini-website. Users create new nodes in the hierarchy each time that they want to elaborate, change or add content. Using Wikis can allow for a numerous opportunities for collaboration between students, but students do not have to be in the same physical location to meet with each other. These kinds of programs allow for cooperation between the instructor and students or among students by using different formats of social interaction (Godwin-Jones 2005). For language courses, since this collaboration can be in the target language, students are using their L2 to communicate and construct knowledge for real purposes outside of class.

\section{Interface}

Institutions and individuals can use the Wiki module in an LMS such as Moodle or Sakai, or a Wiki program can be installed on a server as a stand-alone program. One such stand-alone program is PMWiki5, which can be downloaded for free. There are several skins, or templates, that are packaged with the program, or the site administrator can create his or her own. The Wiki modules in Moodle and Sakai can also work in stand-alone mode on a single computer if there is no access to a server.

Comparing the user interface of PMWiki, Moodle, and Sakai, Moodle has the most transparent and easiest navigation (Image 1), especially for a generation of students and faculty well-versed in text editing in programs such as Microsoft Word. PMWiki's interface (Image 2) resembles programming code and could be an obstacle for students with less technology experience. Sakai's Wiki tool has both clickable commands as well as the option to use HTML tags such as $<\mathrm{H} 1>$ for a large heading (Image 3 ).

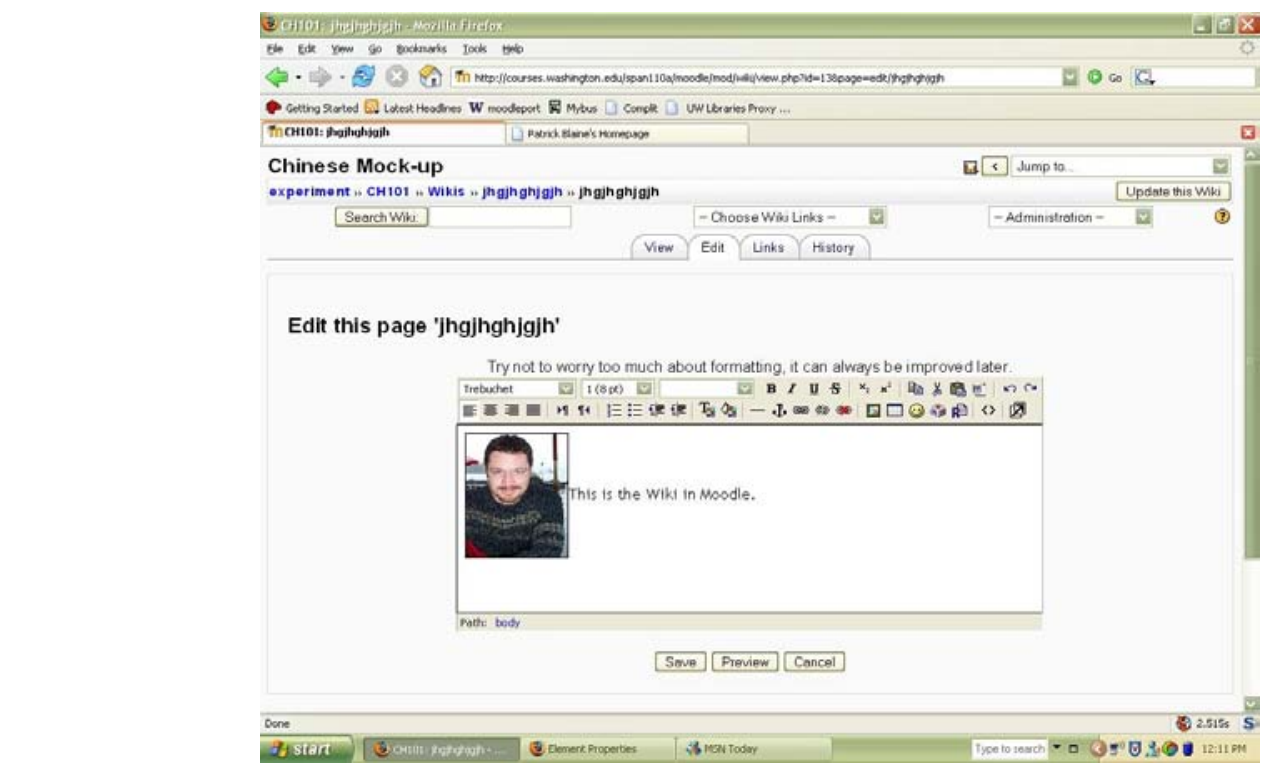

Image 1: Moodle Wiki Editing 
Yaden \& Blaine

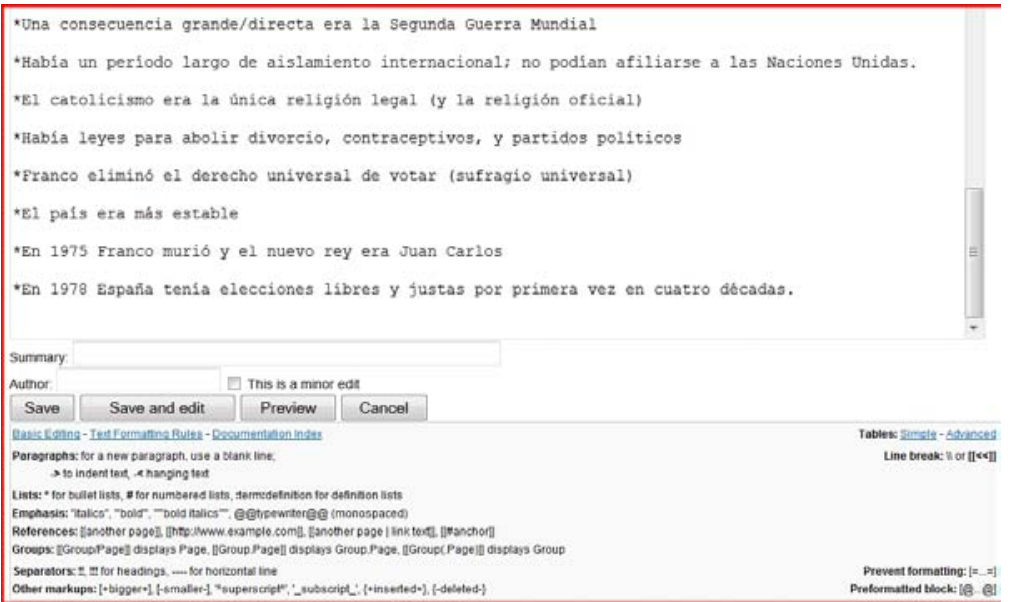

Image 2: PMWiki Editing

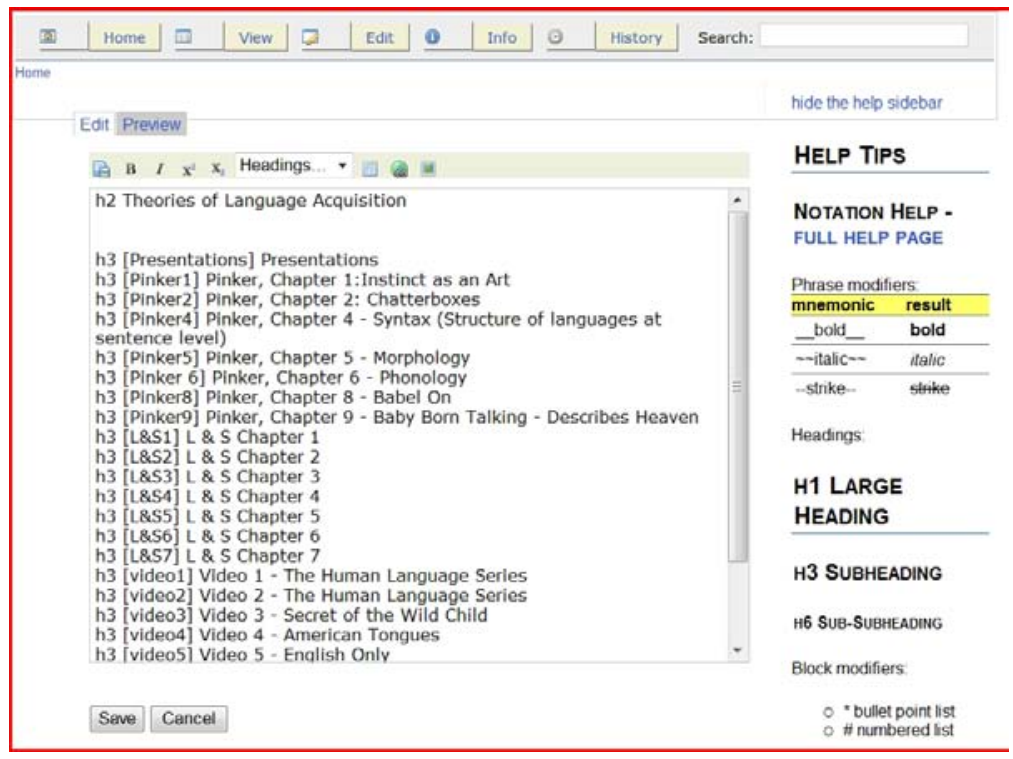

Image 3: Sakai Wiki Editing 


\section{Pedagogical Uses}

The current project describes pilots of the Wiki tool in a 400-level linguistics course on theories of language acquisition, a 300-level Spanish language and culture course, and a 300-level Spanish cinema course. This article will explain the projects, summarize the students' evaluation of Wikis, and address challenges encountered during the projects' terms.

For the theories of language acquisition course, the students created their daily study guides for their nightly readings using a Wiki. One student would post a definition of a term, an example of a new concept, or a question about an issue he or she had not understood in the readings. Another student would go in and modify or add to that definition, give additional examples, or post an answer to another student's questions. The end result was a group-created website with the student-generated content that was then used as the basis for the in-class discussions and quizzes.

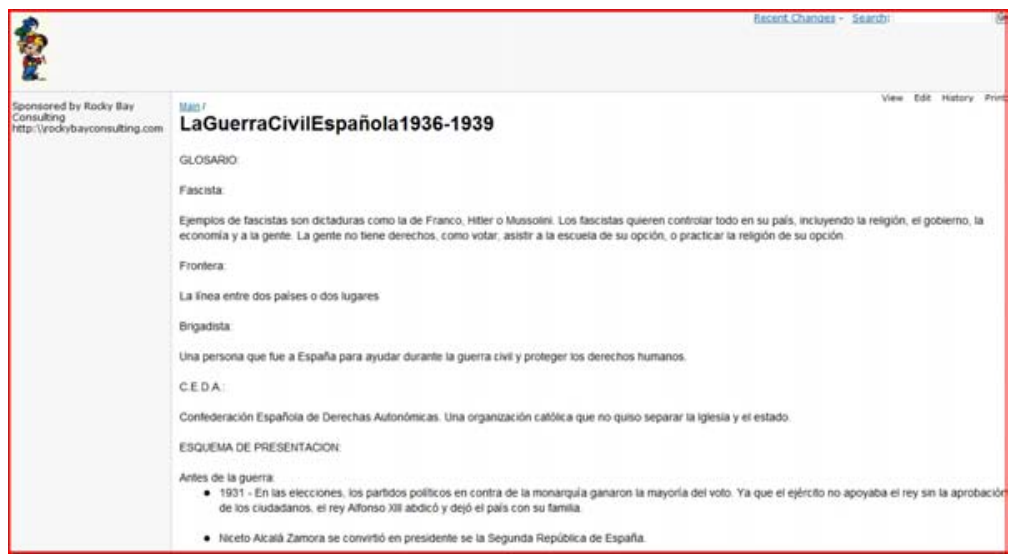

Image 4: Example of student-generated content

For the advanced language and culture class in Spanish that participated in this pilot, students had to give regular group presentations on various topics. Each group created its own Wiki space as the group members planned their presentation outside of class, and then could refer students to the Wiki for a review of the material as a supplement to their in-class oral presentations. Since the language and culture class involved in this study met only 3 hours a week, this additional collaborative tool increased the amount of L2 communication outside of class.

In both of these projects, the Wiki (using PMWiki) was stored on the professor's personal server and a link to the site was accessible via External Links in their institution's LMS at the time, namely Blackboard. As the university transitions from Blackboard to Sakai, future Wikis will be fully integrated in the course website and no additional program or server will be needed.

A third pilot at a the University of Washington tested Moodle's Wiki function in an upper-level undergraduate Spanish cinema and literature class. The wiki served three purposes in the class. The first 
was to provide an opportunity for asynchronous group work and to promote the feeling among the students of a shared accomplishment. The second was to provide students with a self-created study guide, similar to the goals of the theories course mentioned above. The third was to provide an easy method of evaluation, based on the students' contributions to the group project. Each student was required to generate one film review/guide and two film terms.

\section{Results of Pilot Projects}

To assess these projects more formally, we administered a student satisfaction survey specific to the Wiki project at the end of the semester in two of the three courses, and referred to the general course evaluations for all three courses. The survey questions specific to the Wiki project are listed in Appendix I. Utilizing the quiz/survey function of the LMS, students' opinions were quickly and easily assessed. The results of the survey for two of the three pilot projects are listed in Table 2 and Table 3 below. The third course was done using a different LMS (Moodle) and an informal survey was conducted using the student course evaluations at the end of the course.

Student Survey of Wiki Projects

Table 2: Theories of Language Acquisition (Language 446 - $88 \%$ response rate)

\begin{tabular}{llllll}
\hline Response & Ease of use & $\begin{array}{l}\text { Enhanced } \\
\text { learning }\end{array}$ & $\begin{array}{l}\text { Useful for } \\
\text { exam prep }\end{array}$ & $\begin{array}{l}\text { Useful for } \\
\text { class } \\
\text { discussions }\end{array}$ & $\begin{array}{l}\text { Fair } \\
\text { assessment }\end{array}$ \\
\hline $\begin{array}{l}5-\text { strongly } \\
\text { agree }\end{array}$ & $14 \%$ & $43 \%$ & $57 \%$ & $14 \%$ & 0 \\
$4-$ agree & $71 \%$ & $57 \%$ & $29 \%$ & $14 \%$ & $43 \%$ \\
$3-$ neutral & $14 \%$ & 0 & $14 \%$ & $57 \%$ & $14 \%$ \\
$2-$ disagree & 0 & 0 & 0 & $14 \%$ & $43 \%$ \\
$\begin{array}{l}1-\text { strongly } \\
\text { disagree }\end{array}$ & 0 & 0 & 0 & 0 & 0 \\
\hline
\end{tabular}

Table 3: Advanced Language and Culture (Spanish $301-60 \%$ response rate)

\begin{tabular}{lllllll}
\hline Response & Ease of use & $\begin{array}{l}\text { Enhanced } \\
\text { learning }\end{array}$ & $\begin{array}{l}\text { Useful for } \\
\text { exam prep }\end{array}$ & $\begin{array}{l}\text { Useful for } \\
\text { class } \\
\text { discussions }\end{array}$ & $\begin{array}{l}\text { Improve L2 } \\
\text { skills }\end{array}$ & $\begin{array}{l}\text { Fair } \\
\text { assessment }\end{array}$ \\
\hline $\begin{array}{l}5-\text { strongly } \\
\text { agree }\end{array}$ & $12 \%$ & $12 \%$ & $25 \%$ & 0 & 0 & $12 \%$ \\
\hline
\end{tabular}




\begin{tabular}{|c|c|c|c|c|c|c|}
\hline 4 - agree & $62 \%$ & $25 \%$ & $25 \%$ & $25 \%$ & $38 \%$ & $38 \%$ \\
\hline 3 - neutral & $12 \%$ & $62 \%$ & $25 \%$ & $50 \%$ & $50 \%$ & $12 \%$ \\
\hline 2 - disagree & $12 \%$ & 0 & $25 \%$ & $25 \%$ & $12 \%$ & $38 \%$ \\
\hline $\begin{array}{l}1 \text { - strongly } \\
\text { disagree }\end{array}$ & 0 & 0 & 0 & 0 & 0 & 0 \\
\hline
\end{tabular}

The results varied by course. In the theories course, the instructor took a hands-off approach, letting the students fully control the Wiki. Also, the Wiki tool clearly replaced a course requirement (daily study guides) instead of simply being another add-on. The students in this course are "language aficionados," most of whom plan to become language teachers, so their interest and commitment to a new learning tool was more inherent. The students, as a result, had mainly positive reactions to the Wiki projects. One student commented that overall it was a useful tool and a good way to put a summary of the class content together in a way that the whole class could benefit. Another student mentioned that combined with the discussion board, it allowed the class to carry on dialogue with varying view-points that offered a more holistic learning experience.

The Spanish language and culture class took on a very different personality than the theories course. The instructor was heavily involved in the Wiki, posting much more frequently than the students and constantly changed and corrected content. Using the history tool, students could see that their project was modified by the instructor, and they in turn lost interest in continuing to develop the Wiki. The Wiki project was judged by students to be an unclear add-on to "homework/participation," and their dissatisfaction with the Wiki was evident because $50 \%$ responded that they disagreed or were neutral that the Wiki provided a fair assessment of their effort in the course. This dissatisfaction was expressed in a written comment by one student who said she understood that it is hard to grade participation because often, other people post the same things you would had. One student expressed that if Wiki were to have a greater effect it would have to play a much larger role. As it is, the same could be provided in the Discussion Board.

The instructor of the Spanish film course observed that while it was difficult to get the students to make consistent improvements to the Wiki, they eventually began to work more with the project and to become more enthused. The Wiki project was assessed in the general evaluations of the course. One student, responding generally to the question what aspects of this class detracted from your learning? answered: There were not enough people enrolled to participate fully in the online "Wike (sic) de Repaso". There could have been further discussion here if it were more critical to class grade. A student suggested that the instructor [p]erhaps include more writing workshop opportunities, where students can critique each other's papers. This kind of peer-review editing of papers would be an excellent use of the Wiki function and should be considered in future Wiki projects. Overall, the evaluations for the 
course fell into Excellent or Very Good for every category and there were no additional comments specific to the Wiki project.

\section{Challenges}

As with any new technology, it is important to consider seriously the challenges and weigh them against the potential pedagogical benefits. The main challenges we found in the current pilot projects are assessment, pedagogical beliefs, and technological learning curve for students and faculty.

The biggest challenge was assessment. As seen in the survey results above, this is one area in which students were the least satisfied. Students were assessed on their participation in the Wiki, both through self-assessments as well as instructor assessments using the history function built into the program. Any user can click on history and see who has made each contribution, and the date and time of each contribution.

In the theories course, $10 \%$ of the student's final grade (pass/fail) was based on regular, consistent contributions to these spaces. Both regular and consistent are hard to define, and the comments showed that students preferred more specific guidelines, such as 3 unique posts per week, minimum of 20 words per post. For the 300-level culture course in Spanish, the Wiki project was built in to the overall homework and participation grade and was worth $20 \%$. It was not surprising that students felt even more ambivalent about the fairness of this assessment. The instructor for the Cinema course wanted the Wiki experience to be as informal as possible, so that they might enjoy it a bit more than formal assignments. Fulfilling the requirement was worth $15 \%$ of their grade (pass/fail).

As with many areas where a particular assignment is graded pass/fail, participation can seem to be difficult to define and assess. One useful tool is to encourage self-assessment by having students complete a participation self-evaluation once or twice throughout the term (Table 4). The instructor responds to the self-evaluation by either agreeing or disagreeing, and adding encouraging comments that will help keep the project's momentum growing.

*Please use this self-evaluation form to reflect on your on-line participation to date in our course. As discussed in class and stated in the syllabus, these dynamic resources that we are constructing as a class take the place of daily written study guides, and help tie together all of the readings, discussions, and films. They will also be useful tools when preparing for exams.

Take a look at our eCourse and evaluate yourself on both your regularity (consistency) of participation as well as the depth of your contribution to the discussions / posts. Click on "history" to see dates, times, and names of posts to help in your self-assessment.

- Regularity: / 50

- Depth of contributions: $/ 50$

- Total: /100

- Comments: 
- How can I improve my participation in the Wiki?:

- Instructor: I __--- agree _-_-_disagree with your self-assessment because:

Student Signature \& Date

Table 4: Sample self-assessment
Instructor Signature \& Date

Another difficulty in integrating Wikis successfully stems from the pedagogical beliefs of both the instructors and the students. Any switch to a student-centered approach can be a radical change for traditional classroom settings. The "learning curve" for useful pedagogical implementation of any new technology tool can seem daunting. Using student-created Wikis as a major content source shifts the creation and ownership of knowledge base from the instructor to the student. The role of student in these Wiki projects is that of primary content producer. The instructor's role changes to one of facilitating, keeping students on-track, giving ideas for missing pieces, and perhaps correcting errors. Some instructors will have more difficulty giving up this role than others, depending on their beliefs about how languages are best learned in a classroom setting. In fact, Ertmer describes the final frontier of successfully integrating technology to be to arrive at the point where teachers hold personal beliefs aligned with a constructivist pedagogy (Ertmer 2005).

A third challenge is the technological learning curve, both for faculty and students. Wikis are quite straightforward, and although in a program like PMWiki, on the surface the editing may look a little like typing HTML code, it is in fact much simpler. A quick tutorial on the editing tools or a short handout (see Appendix II) is all that was needed in the test cases. Moodle and Sakai have Wiki interfaces that resemble common word processing programs, so faculty and students alike may find it quite easy to use.

\section{Conclusion}

Using Wikis in an LMS such as Sakai or Moodle can be a useful teaching tool for language courses, one that enhances and increases collaboration outside of class. Wiki projects can help support a student-centered learning experience. Of course, with any new technology, an instructor has to weigh the pros and cons from a pedagogical perspective. Facilitating the Wiki and making sure students stay active and on-track may require increased management and preparation time, and the learning curve for teachers will depend on previous experience with technology and on the instructor's belief in the effectiveness of a constructivist, student-centered teaching approach.

With all technology for teaching purposes, it is important to first decide whether the new technology will do something at least as well if not better than what is already being accomplished in a class via more traditional means. For example, if an instructor has difficulty getting students to collaborate outside of class in the target language and their schedules seem to make it impossible to find common time to meet for group projects, then an online environment such as a Wiki may be a good tool. This solution also allows the groups to share their content with their instructor and their classmates 
asynchronously, at any time that is convenient.

As with many online tools, Wikis and other modules in Sakai or Moodle do not replace face-to-face classroom interactions, especially in language courses. For example, a study on the effectiveness of hybrid Spanish courses at the University of Washington with a heavy (50\%) web-based context found that students did not do worse nor perform better than their classmates in a traditional setting, but that they did express more dissatisfaction with their overall learning experience (Fox \& Brandl 2001). These findings indicate that instead of using programs such as Moodle and Sakai to replace contact time, a more successful direction for implementation could involve using them to complement classroom teaching and provide a greater variety of asynchronous activities for students to perform outside of class. The findings also point towards the importance of carefully designing the types of interactions that students will have with an LMS, as well as trying to maintain as much curricular flexibility as possible in order to respond to student academic performance and general satisfaction.

Based on these three pilot projects, we conclude that the two most important factors to consider when implementing a Wiki are how to integrate the Wiki project and how to assess student learning and participation in the Wiki project. Faculty integrating Wikis into their courses must be able to articulate clearly to students the usefulness of the Wiki and to develop Wiki projects that meet specific course objectives. Students are quick to realize when a project is an "add-on" requirement and perceive this as extra busy work. Faculty must provide a clear assessment procedure that will be as objective as possible. In addition to using student self-assessments, this procedure could also include more specific requirements concerning the number and length of each post, or could include a note grade instead of pass-fail based on content and form. Finally, to maintain the integrity of truly student-generated content, faculty must provide attentive guidance to the projects without being overbearing.

By carefully designing the implementation, integration, and evaluation of a Wiki, a new, enjoyable collaborative space can be created which allows for much more efficient, asynchronous, and evaluated interaction between groups of students and teachers. Also, the flexibility of this medium allows for extremely varied adaptations in an extraordinarily large range of educational contexts. Although Wikis do require some measure of initial and ongoing supervision from the instructor, they provide a fun, relevant way to evaluate and encourage student progress with the possibility of creating projects of lasting benefit, in addition to providing students with valuable experience in using online collaboration tools.

Notes

1. Moodle.com is the commercial hosting site for Moodle.org, which is the main page, and where the community forums and documentation are held.

2. http://www.moodle.org

3. http://depts.washington.edu/llc

4. http://www.sakaiproject.org/

5. http://www.pmwiki.org/

\section{Appendix I: Student survey}

Please mark your response to each of the statements below about the Wiki in your eCourse, using 
the following scale:

5-strongly agree 4 -agree 3 -neutral $\quad$ 2-disagree 1 -strongly disagree

1. The Wiki was easy to use.

2. Participation in the Wiki enhanced my learning in this course.

3. The content of the Wiki helped me prepare for exams.

4. The content of the Wiki helped me prepare for in-class discussions.

5. Having the Wiki participation part of my course grade is a fair assessment of my effort in the course.

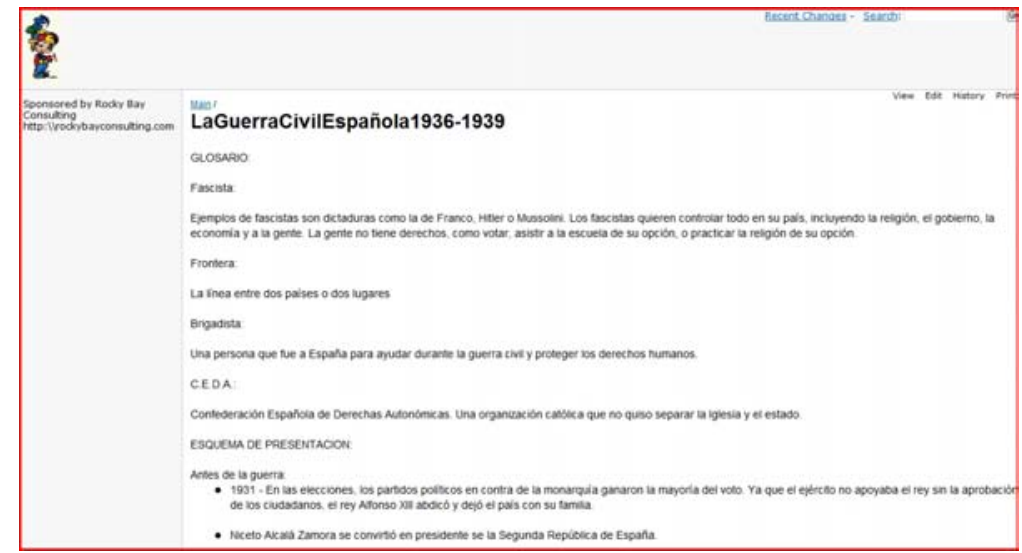

\section{Appendix II: WIKI editing tips (PMWiki)}

GENERAL:

To make a change at any point, click "Edit".

Be sure to put your name in the "Author" box before you save your changes, to get credit for your postings.

Click "save" and you'll see your changes!

FORMATTING:

These formatting steps will make the WIKI more readable for everyone. Don't be shy - try the steps below to play around with the page. If you make a mistake, you or any of your classmates can go in and fix it up!

- MAKING NEW PAGES: To make a link to a new page (for example, a link to a new topic area, chapter, etc.): Type the name you want to give the page between double brackets, such as [[Spanish Civil War]]. When you do this, before any content has been added to this new page you will see a "?". Click on the link to add new text.

- LISTS: To make a list, type \# for numbered (ordered) lists, ${ }^{*}$ for bulleted lists. 
- HEADING (this really helps with the overall layout and readability!): Start with !! for subheading, and !!! for a sub-subheading.

- ITALICS: type the word between 2 SINGLE quotes "example" = example

- BOLD: type the word between 3 SINGLE quotes "'example"' = example

\section{EXAMPLES:}

If you click on "EDIT" for any of the pages, you can see samples of the formatting codes in action. For example:

!!!Vocabulary

*"Linguistics:" the study of language

*"Morphemes:" Smallest unit of a language that carries meaning

*"Semblance:" an outward or token appearance of that form that is deliberately misleading

Gives you a page that when saved looks like:

Vocabulary

- Linguistics: the study of language

- Morphemes: Smallest unit of a language that carries meaning

- Semblance: an outward or token appearance of that form that is deliberately misleading

\section{References}

Brandl, K. (2002, March). Students' Attitudes and Perception of Learning: a Comparative Study of a Web-based and Classroom-based Language Course. CALICO 2002. Annual Conference, March 27-31. Davis, CA.

Brandl, K. (2005). Are you Ready to "MOODLE"? Language Learning and Technology 9(2): 16-23. Retrieved April 7, 2006, from http://llt.msu.edu/vol9num2/review1/.

Branzburg, J. (2005). Using the Moodle Course Management System. Technology and Learning 26(1): 40.

Ertmer, P. (2005). Teacher Pedagogical Beliefs: the Final Frontier in our Quest for Technology Integration. Educational Technology Research and Development 53(4): 25-39.

Fiori, M. (2005). The Development of Grammatical Competence through Synchronous Computer-mediated Communication. CALICO Journal 22(3): 567-601.

Fox, J. \& Brandl, K. (2001, October). Taking Language Instruction Online: Progress or Demise? Paper presented at the annual meeting of the Washington Association of Foreign Language Teachers. October 12-13. Pasco, WA.

Godwin-Jones, R. (2005). Blogs and Wikis: Environments for Online Collaboration. Language Learning and Technology 7(2): 12-16. Retrieved April 7, 2006, from http://llt/msu.edu/vol7num2/emerging/.

Godwin-Jones, R. (2005). Messaging, Gaming Peer-to-Peer Sharing: Language Learning Strategies and Tools for the Millennial Generation. Language Learning and Technology 9(1): 17-22. Retrieved April 7, 2006, from http://llt.msu.edu/vol9num1/emerging/.

Lightbown, P. \& Spada, N. (1999). How Languages are Learned. Oxford: Oxford University Press.

Richards, J. \& Rodgers, T. (2001). Approaches and Methods in Language Teaching. Cambridge: Cambridge University Press. 
Salaberry, M. R. (2001). The Use of Technology for Second Language Learning and Teaching: A Retrospective. Modern Language Journal 85(1): 39-56.

Taylor, C. (2005). It's a Wiki, Wiki World. Time 165(23): 40-42.

Warschauer, M. (1997). Computer-Mediated Collaborative Learning: Theory and Practice. Modern Language Journal 81(3): 470-481. 